\title{
Association between C-reactive protein and unrecognised sleep-disordered breathing in the elderly
}

\author{
F. Roche*\#, J-M. Gaspoz*,\#, V. Pichot*, , M. Picard-Kossovsky\#, D. Maudoux*, \\ A. Garcin*, S. Celle*," E. Sforza* and J.C. Barthélémy, ${ }^{\star}$, on behalf of the PROOF and \\ SYNAPSE Study Groups
}

ABSTRACT: Elevated levels of $\mathrm{C}$-reactive protein (CRP) have been reported in patients with sleep-disordered breathing (SDB) and may represent an inflammatory marker of cardiovascular risk. However, the association of CRP with SBD in presumed healthy elderly subjects is unknown.

In total, 851 (58.5\% females) 68-yr-old subjects, who were free of any known cardiac or sleep disorders, were prospectively examined. Subjects underwent unattended polygraphy, and the apnoea/hypopnoea index ( $\mathrm{AHI}$ ) and oxyhaemoglobin desaturation index (ODI) were assessed. Elevated levels of CRP were found on the morning after the sleep study in patients with more severe SDB. A significant correlation was found between CRP levels, time spent at night with arterial oxygen saturation $<90 \%$ and ODI. No association was found between CRP levels and AHI. After adjustments for body mass index, smoking status, hypertension, diabetes and dyslipidaemia, a significant association remained between CRP levels and ODI $>10$ events $\cdot h^{-1}$.

CRP levels were frequently increased in a large sample of elderly subjects free of major cardiovascular disease. CRP levels were not correlated with the AHI and the indices of sleep fragmentation; the ODI $>10$ events $\cdot h^{-1}$ was the strongest predictor of raised CRP level.

The present results suggest that, in the elderly, intermittent hypoxaemia may underlie inflammatory processes leading to cardiovascular morbidity.

KEYWORDS: C-reactive protein, elderly, hypoxaemia, inflammation, sleep apnoea

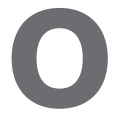
bstructive sleep apnoea syndrome (OSAS) is a highly prevalent disorder affecting $2-4 \%$ of the general population and is considered an independent risk factor for cardiovascular diseases [1-3], particularly hypertension, coronary artery disease, heart failure and stroke [4, 5]. Furthermore, newly diagnosed OSAS patients, free of classical cardiovascular risk factors, such as hypertension, diabetes and smoking, may have early signs of atherosclerosis [6]. Although the pathophysiology of cardiovascular risk is mutifactorial, sympathetic hypertonia [7], endothelial dysfunction [8, 9] and insulin resistance [10] have been postulated as factors initiating and sustaining inflammatory microvascular alterations and therefore atherosclerosis [11, 12]. In middle-aged OSAS patients, C-reactive protein (CRP), a marker of inflammation in atherosclerotic lesions [13], is elevated in severe cases [14] and decreases after treatment with nasal continuous positive airway pressure [15]. Despite the putative role of CRP in cardiovascular risk in OSAS, studies conducted to date have yielded contradictory results, with some showing an independent association with disease severity in adults [16-19] and children $[20,21]$, and others showing no relationship [22, 23]. Moreover, the association between obesity and CRP [24] raised the question as to whether elevated CRP reflects the effects of obesity or whether it is specific to OSAS itself.

In the elderly, the prevalence of sleep-disordered breathing (SDB) is estimated to be higher than in middle-aged subjects. ANCOLI-IsRAEL et al. [25] reported that, in a community-dwelling elderly population, $62 \%$ had a respiratory disturbances index $>10$ and $44 \%>20$. The prevalence rate of SDB was $15 \%$ in the general population when the criterion of an apnoea/hypopnoea index (AHI) of $\geqslant 15$ was used [26]. Despite the high incidence of $\mathrm{SDB}$, the clinical spectrum of the disease appears to be different, elderly patients have shown a lower incidence of sleepiness and hypertension compared with middle-aged patients [27], and have a different prognosis when treated [28, 29].
AFFILIATIONS

* Service de Physiologie Clinique et de l'Exercice, CHU Nord, and "Faculté de Médecine Jacques Lisfranc, Université Jean Monnet, PRES de Lyon,

Saint-Etienne, France.

"Division of Primary Care Medicine, Dept of Community Medicine and Primary Care, University Hospitals Geneva, Switzerland.

CORRESPONDENCE F. Roche

Service de Physiologie Clinique et de I'Exercice

EFCR

CHU Nord - Niveau 6

F-42055 Saint-Etienne Cedex 2

France

Fax: 33477828447

E-mail: Frederic.Roche@univ-stetienne.fr

Received:

February 132008

Accepted after revision:

November 262008

SUPPORT STATEMENT

The present study was supported by a grant from the French Minister of Health (Cellule Projet Hospitalier de Recherche Clinique National,

Direction de la Recherche Clinique (CHU; Saint-Etienne, France), Appel d'Offre 1998 and Appel d'Offre 2002) and by Association de Recherche SYNAPSE (Saint-Etienne, France).

STATEMENT OF INTEREST

None declared.

European Respiratory Journal Print ISSN 0903-1936 Online ISSN 1399-3003 
Therefore, an interesting, but still unanswered question is whether CRP levels are increased in elderly subjects having undiagnosed OSAS and whether higher CRP levels predict the risk of future cardiovascular morbidity among persons without known cardiovascular disease.

The aim of the current study was to assess the association between SDB and CRP levels in a large prospective population-based cohort of elderly subjects examined to evaluate the possible role of SDB in cardiovascular risk generation. Specifically, the present authors focused on the relationship between apnoea density, sleep fragmentation, hypoxaemia and CRP as a marker of inflammatory processes.

\section{METHODS}

\section{Population}

The present investigation is part of the PROOF study, a population-based cohort study of 1,011 (61\% females) volunteers aged $65 \pm 1$ yrs living in the town of Saint-Etienne (France) who were enrolled to assess whether an age-related decrease in autonomic nervous system activity could represent an independent risk for cardiovascular mortality, silent and symptomatic ischaemic stroke, myocardial infarction and newonset heart failure [30]. An ancillary study addressing the association between SDB and cardiovascular and cerebrovascular morbidity during a 7-yr follow-up was proposed to participants (SYNAPSE study). Exclusion criteria for entry in the present study were history of myocardial infarction, heart failure, stroke, pacemaker therapy, previously diagnosed or treated OSAS, type 1 diabetes mellitus, symptoms or signs of acute or chronic inflammation and use of corticosteroids and/ or antibiotics for the 3 weeks preceding recruitment. Participants with hypertension were kept in the study if their condition was controlled under anti-hypertensive medications.

Of the original sample, 851 (58.5\% females) subjects participated in the SYNAPSE study between March 2003 and June 2005. The PROOF and SYNAPSE studies were approved by the local ethics committee (CCPRB Rhone-Alpes Loire, France) and all subjects gave written consent to study participation.

\section{Clinical data}

All subjects underwent a clinical assessment including a questionnaire on demographics, medical history and medication, measurements of body mass index (BMI) and neck circumference and an evaluation of sleepiness using the Epworth sleepiness scale. Detailed clinical assessment was specially focused on cardiac and cerebrovascular disease, hypertension, obstructive or restrictive lung disease, metabolic disorders, psychiatric diseases and current medication. Subjects were defined as normotensive if they did not report history of hypertension and antihypertensive treatment and they did not have a mean systolic ambulatory blood pressure (ABP) <135 mmHg (Diasoft, Novacor, Rueil Malmaison, France) and a mean diastolic ABP $<85 \mathrm{mmHg}$.

\section{Sleep study}

A nocturnal unattended sleep study was performed at-home in all subjects using a polygraphic system (HypnoPTT; Tyco Healthcare, Puritan Bennett, Boulder, CO, USA), which included the following parameters: sound measurement, electrocardiography, pulse transit time, heart rate, airflow by nasal pressure, respiratory effort and body position. Arterial oxygen saturation was measured by pulse oximetry $\left(S_{\mathrm{p}}, \mathrm{O}_{2}\right)$. A software package was used for downloading and analysing tracings. A recording duration of $\geqslant 5 \mathrm{~h}$ was required for validation, and a second night of monitoring was performed when subjective sleep latency exceeded $2 \mathrm{~h}$ on the first night, or when respiratory parameters were missing. All recordings were visually validated and manually scored for respiratory events and nocturnal $\mathrm{Sp}, \mathrm{O}_{2}$ according to standard criteria [31]. Hypopnoea was defined as $\geqslant 50 \%$ reduction in airflow from the baseline value lasting $\geqslant 10 \mathrm{~s}$ associated with $\geqslant 3 \%$ oxygen desaturation. Apnoeas were defined as the absence of airflow on the nasal cannula lasting for $\geqslant 10 \mathrm{~s}$. The absence of rib cage movements associated with an apnoea was defined as central, while a progressive increase in pulse transit time was defined as obstructive. The AHI was established as the ratio of the number of apnoea and hypopnoea events per hour of recording. Indices of nocturnal hypoxaemia were as follows: mean $\mathrm{Sp}_{\mathrm{p}} \mathrm{O}_{2}$; percentage of recording time $\mathrm{Sp}_{\mathrm{p}} \mathrm{O}_{2}<90 \%$; minimal $\mathrm{Sp}, \mathrm{O}_{2}$ value recorded during sleep and the oxygen desaturation index (ODI), i.e. the number of episodes of oxygen desaturation per hour of recording time during which blood oxygen fell by $\geqslant 3 \%$. Pulse transit time was continuously monitored and, according to previously defined criteria [32], an autonomic respiratory-related arousal index (AAI) was calculated (arousals following a defined respiratory event). To minimise potential overestimation of sleep duration, subjects completed a sleep diary to exclude wakefulness before turning lights off from the analysis. An AHI $>15$ events $\cdot h^{-1}$ [26] with $\geqslant 85 \%$ of events scored as obstructive or an ODI $>10$ events $\cdot h^{-1}[33$ ] was considered a diagnostic of SDB. An AHI $>15-30$ events $\cdot h^{-1}$ indicated mild OSAS and $>30$ events $\cdot h^{-1}$ indicated moderateto-severe OSAS.

\section{CRP levels}

Blood samples for measurement of plasma CRP levels were collected in all subjects on the morning after the sleep study. Plasma CRP levels were measured with a flex reagent cartridge, which is based on a particle-enhanced, turbidimetric immunoassay technique (Roche Diagnostic GmbH, Mannheim, Germany) allowing a detection level of $0.2 \mathrm{mg} \cdot \mathrm{L}^{-1}$ and exhibiting linear behaviour up to $25 \mathrm{mg} \cdot \mathrm{L}^{-1}$ with intra-assay and inter-assay coefficients of variability of $9 \%$ and $18 \%$, respectively. Fasting glycaemia, serum lipid levels, including triglycerides and total high-density lipoprotein and calculated low-density lipoprotein cholesterol, were also assessed.

\section{Statistical analysis}

Results are presented as mean $\pm \mathrm{SD}$, unless otherwise indicated. All reported p-values are two-tailed, with a statistical significance of $<0.05$. Anthropometric, clinical and sleep study data are presented using descriptive statistics (mean, SD, range and percentage of subjects). ANOVA and post hoc analyses were performed to compare CRP levels with groups of subjects according to AHI, ODI and AAI quartiles.

Since plasma CRP levels were not normally distributed, logarithmic transformation was used to achieve a distribution close to normality. Linear regression analysis was used to explore the relationship between log CRP and SBD severity defined by the ODI, AAI and AHI, all variables considered are 


\begin{tabular}{|c|c|c|}
\hline TABLE 1 & \multicolumn{2}{|c|}{$\begin{array}{l}\text { Demographic, anthropometric and clinical data } \\
\text { of the study group }\end{array}$} \\
\hline \multicolumn{3}{|l|}{ Clinical data } \\
\hline Age yrs & & $68.1 \pm 1.1$ \\
\hline $\mathrm{BMI} \mathrm{kg} \cdot \mathrm{m}^{-2}$ & & $25.3 \pm 3.7$ \\
\hline Neck circu & erence $\mathrm{cm}$ & $37.1 \pm 4.0$ \\
\hline Systolic AE & $\mathrm{mmHg}$ & $118.8 \pm 13.8$ \\
\hline Diastolic A & $\mathrm{mmHg}$ & $74.0 \pm 8.4$ \\
\hline CRP serun & evel $\mathrm{mg} \cdot \mathrm{L}^{-1}$ & $2.26 \pm 1.83$ \\
\hline ESS & & $5.7 \pm 3.6$ \\
\hline \multicolumn{3}{|c|}{ Sleep study data } \\
\hline AHI events & & $20.4 \pm 14.8$ \\
\hline ODI events & & $9.4 \pm 9.5$ \\
\hline Time $\mathrm{Sp}, \mathrm{O}_{2}$ & $90 \% \%$ & $2.0 \pm 6.7$ \\
\hline Mean $\mathrm{Sp}, \mathrm{O}$ & & $95.4 \pm 1.6$ \\
\hline Minimal $S p$ & & $89.8 \pm 4.1$ \\
\hline AAl events & & $15.4 \pm 10.5$ \\
\hline
\end{tabular}

Data are presented as mean \pm SD. BMI: body mass index; ABP: ambulatory blood pressure; CRP: C-reactive protein; ESS: Epworth Sleepiness Scale; AHI: apnoea/ hypopnoea index; $\mathrm{ODI}$ : oxygen desaturation index; $\mathrm{Sp}, \mathrm{O}_{2}$ : arterial oxygen saturation measured by pulse oximetry; AAl: autonomic respiratory-related arousal index.

shown in quartile distribution. Multiple logistic regression models were constructed to test for independent associations between the presence of SDB (independent variable: AHI), autonomic sleep fragmentation (independent variable: AAI), or hypoxaemic load (independent variable: ODI) and log CRP. Unadjusted odds ratios (ORs) and 95\% confidence intervals (CIs), as well as adjusted ORs and 95\% CIs, were calculated.

\section{RESULTS}

\section{Clinical and sleep study data}

Demographic, anthropometric and nocturnal parameters are summarised in table 1 . The age of the total sample of 851 subjects was $68 \pm 1.1 \mathrm{yrs}$ and $41.5 \%$ were male.

In total, $12.3 \%$ of subjects met the criteria for obesity defined as a BMI $>30 \mathrm{~kg} \cdot \mathrm{m}^{-2}$, whereas $38.5 \%$ were classified as overweight (BMI $>25 \mathrm{~kg} \cdot \mathrm{m}^{-2}$ ). The prevalence of treated hypertension was $43.1 \%$ and $76(8.7 \%)$ subjects had clinical newly diagnosed systolic and/or diastolic hypertension (incident hypertension). In treated patients, $64 \%$ received $\beta$-blockers and/or diuretics and/or calcium channel blockers and 58\% received angiotensin-converting enzyme-inhibitors and/or angiotensin II receptor inhibitors. Hypercholesterolaemia was found in $35.1 \%$ of subjects, 201 subjects were receiving statins. A clinical history of diabetes was reported by $5.3 \%$ of subjects.

SDB was identified in $482(56.8 \%)$ subjects, with $315(37.1 \%)$ having a mild form (AHI 15-30 events $\cdot \mathrm{h}^{-1}$ ) and $167(19.7 \%)$ having a moderate-to-severe form $\left(\mathrm{AHI}>30\right.$ events $\left.\cdot \mathrm{h}^{-1}\right)$. Based on the oxygen desaturation values, 296 (34.8\%) had an ODI $>10$ events $\cdot h^{-1}$. Time spent with $\mathrm{Sp}, \mathrm{O}_{2} \quad<90 \%$ reached $2.01 \pm 6.6 \%$ (range $0-100 \%$ ), with a 90th percentile threshold of $4.44 \%$. Autonomic sleep fragmentation was moderate in 306 $(36.2 \%)$ and severe in $79(9.4 \%)$ cases.

In the SYNAPSE study subjects, the mean CRP level was $2.26 \pm 1.83 \mathrm{mg} \cdot \mathrm{L}^{-1}$. In adults, CRP levels $<1 \mathrm{mg} \cdot \mathrm{L}^{-1}$ are considered low risk, $1-3 \mathrm{mg} \cdot \mathrm{L}^{-1}$ medium risk and $>3 \mathrm{mg} \cdot \mathrm{L}^{-1}$ high risk. In the current study, $29.3 \%$ of subjects were low risk, $50 \%$ of subjects had a medium risk and $20.7 \%$ had a high risk CRP level. CRP levels $>10 \mathrm{mg} \cdot \mathrm{L}^{-1}$ were found in 38 participants. Thus, 813 participants were included in the final analysis that focused on sub-clinical inflammation (CRP level $\leqslant 10 \mathrm{mg} \cdot \mathrm{L}^{-1}$ ).

\section{Variation of the CRP levels by participant characteristics}

In unadjusted analyses, CRP levels did not vary significantly with sex $\left(2.24 \pm 1.95\right.$ versus $2.27 \pm 1.74 \mathrm{mg} \cdot \mathrm{L}^{-1}$ in males and females, respectively; $\mathrm{p}=0.83$ ). In contrast, current/past smoking $\left(2.50 \pm 2.19\right.$ versus $\left.2.18 \pm 1.69 \mathrm{mg} \cdot \mathrm{L}^{-1} ; \mathrm{p}=0.04\right)$ and hypertension $\left(2.54 \pm 1.96\right.$ versus $\left.2.06 \pm 1.70 \mathrm{mg} \cdot \mathrm{L}^{-1} ; \mathrm{p}=0.002\right)$ were associated with higher CRP levels. CRP levels also varied significantly with BMI $(\rho=0.27, p<0.0001)$ for all subjects $\left(4.09 \pm 3.84\right.$ versus $2.62 \pm 5.45 \mathrm{mg} \cdot \mathrm{L}^{-1}$ in obese and normal BMI participants, respectively; $\mathrm{p}=0.003$ ) and in the overweight group $\left(4.09 \pm 3.84\right.$ versus $2.99 \pm 3.36 \mathrm{mg} \cdot \mathrm{L}^{-1}$ in obese and overweight subjects, respectively; $\mathrm{p}=0.03$ ). Linear regression analysis between CRP levels and blood pressure showed no significant correlation between log CRP and systolic or diastolic blood pressure in hypertensive subjects. A slight relationship was found between log CRP levels and systolic $(\rho=0.102, p=0.03)$ and diastolic $(\rho=0.108, p=0.02)$ blood pressure in normotensive cases. CRP levels by subgroups of participants categorised by ODI quartiles, AHI quartiles and AAI quartiles are shown in table 2.

\section{Association between log CRP and nocturnal variables}

Table 3 reports Spearman correlation coefficients between nocturnal variables and log CRP. While log CRP levels were strongly correlated with all indices of nocturnal hypoxaemia, no significant relationship was found with AAI and AHI.

TABLE 2 Mean C-reactive protein (CRP) levels according to the severity of oxygen desaturation index (ODI), apnoea/hypopnoea index $(\mathrm{AHI})$ and autonomic respiratory-related arousal index (AAI)

\begin{tabular}{|c|c|c|c|c|c|}
\hline ODI quartiles & CRP $\mathrm{mg} \cdot \mathrm{L}^{-1}$ & $\mathrm{AHI}$ quartiles & CRP $\mathrm{mg} \cdot \mathrm{L}^{-1}$ & AAI quartiles & CRP $\mathrm{mg} \cdot \mathrm{L}^{-1}$ \\
\hline$<2.6$ & $2.04 \pm 1.63$ & $<9.2$ & $2.13 \pm 1.82$ & $<7.7$ & $2.25 \pm 1.83$ \\
\hline $2.6-6.2$ & $2.21 \pm 1.83$ & $9.2-17.1$ & $2.15 \pm 1.72$ & $7.7-13.6$ & $2.17 \pm 1.79$ \\
\hline $6.3-13.1$ & $2.25 \pm 1.95$ & $17.2-28.2$ & $2.19 \pm 1.91$ & 13.6-20.6 & $2.34 \pm 1.93$ \\
\hline$>13.1$ & $2.56 \pm 1.91^{*}$ & $>28.2$ & $2.41 \pm 1.90$ & $>20$ & $2.29 \pm 1.76$ \\
\hline
\end{tabular}

ANOVA and post hoc tests. Data are presented as mean $\pm \mathrm{SD}$, unless otherwise stated. ${ }^{*}: \mathrm{p}<0.05$ lowest quartile versus the highest quartile disorders. 


\begin{tabular}{|c|c|c|c|c|}
\hline \multirow[t]{2}{*}{ TABLE 3} & \multicolumn{4}{|c|}{$\begin{array}{l}\text { Spearman correlation coefficients relating log C- } \\
\text { reactive protein (CRP) with nocturnal parameters }\end{array}$} \\
\hline & Log CRP & AHI & ODI & AAI \\
\hline \multicolumn{5}{|l|}{ AHI } \\
\hline Coefficient & 0.060 & 1 & & \\
\hline $\mathrm{p}$-value & 0.09 & & & \\
\hline \multicolumn{5}{|l|}{ ODI } \\
\hline Coefficient & 0.121 & 0.803 & & \\
\hline$p$-value & 0.006 & $<0.0001$ & & \\
\hline \multicolumn{5}{|l|}{ AAI } \\
\hline Coefficient & 0.037 & 0.799 & 0.652 & 1 \\
\hline $\mathrm{p}$-value & 0.301 & $<0.0001$ & $<0.0001$ & \\
\hline \multicolumn{5}{|c|}{$\mathrm{Sp}, \mathrm{O}_{2}<\mathbf{9 0 \%}$ time $\%$} \\
\hline Coefficient & 0.078 & 0.162 & 0.295 & 0.074 \\
\hline $\mathrm{p}$-value & 0.027 & $<0.0001$ & $<0.0001$ & 0.036 \\
\hline \multicolumn{5}{|l|}{ Minimal $S p, O_{2}$} \\
\hline Coefficient & -0.082 & -0.408 & -0.571 & -0.291 \\
\hline$p$-value & 0.020 & $<0.0001$ & $<0.0001$ & $<0.0001$ \\
\hline \multicolumn{5}{|c|}{ Sleep duration } \\
\hline Coefficient & -0.013 & -0.103 & -0.023 & -0.131 \\
\hline$p$-value & 0.704 & 0.003 & 0.519 & 0.001 \\
\hline
\end{tabular}

Compared with patients without OSAS (first quartile for AHI $<9.2$ ), CRP levels were higher in more severe cases (fourth quartile), although the differences did not reach statistical significance $(p=0.06)$. Using logistic regression analysis before and after adjustments for sex, BMI, smoking habits, diabetes and hypertension (table 4), no significant association between AHI severity $\left(<15,15-30\right.$ or $>30$ events $\left.\cdot h^{-1}\right)$ and log CRP levels was found. When indices of sleep fragmentation were considered, AAI did not show any significant relationship with log CRP, its values being similar even if AAI was higher (table 2).

Mean CRP values according to ODI quartiles are shown in table 2. There was a trend towards a progressive increase in CRP levels according to the occurrence of oxygen desaturation, with higher values found in subjects having an ODI $>13.1$ events $\cdot h^{-1}(p<0.05)$. Using logistic regression analysis, ODI $>10$ events $\cdot h^{-1}$ was associated with increased log CRP levels after adjustments (OR 1.33, 95\% CI 1.08-1.64; $\mathrm{p}=0.0063$; table 5).

\section{DISCUSSION}

To the present authors' knowledge, this is the first epidemiological investigation of the relationship between SDB and CRP serum levels in a large population-based study performed in the elderly. In the current investigation of healthy 68-yr-old subjects without diagnosed OSAS, it was found that after adjustments for relevant covariates affecting CRP levels, the presence of an ODI $>10$ events $\cdot h^{-1}$ was associated with higher levels of serum CRP, the frequency of respiratory events and the indices of sleep fragmentation had no significant effect. These findings suggest that, in OSAS patients, increased levels of CRP may reflect the key role of intermittent hypoxaemia on oxidative stress and, consequently, on cardiovascular risk.

Among mechanisms mediating cardiovascular morbidity and mortality in SDB, CRP has gathered the greatest attention; several investigations demonstrated a link between elevated values of CRP, SDB severity [20-23] and cardiovascular morbidity $[19,24]$. CRP has pro-inflammatory, pro-adhesive and pro-thrombotic effects, properties participating in the formation of atheromatous lesions through reduction of nitric oxide synthesis and induction of particular adhesion molecules in endothelial cells [34]. The link between inflammatory responses, including $\mathrm{CRP}$ levels, and SDB may be related to several factors such as frequency of apnoea, sleep fragmentation and hypoxaemia, all of which up-regulate inflammation and atherosclerotic processes. Recent studies in animals emphasised [35] that intermittent hypoxia is a more potent stimulus for sympathetic activation and hypertension related to episodic re-oxygenation, the latter representing oxidative stress [36] similar to that implicated in ischeamia-reperfusion [37]. Oxidative stress would result in the activation of inflammatory pathways $[38,39]$, such as those mediated by nuclear factor- $\mathrm{\kappa B}$, tumour necrosis factor- $\alpha$, interleukin (IL)- 6 and IL- 8 , all parameters that are found to be elevated in OSAS patients and modified by therapy [21, 25]. Studies in humans [40] have confirmed the key role of chronic intermittent hypoxia, more than that of the AHI, in the development of atherosclerosis in SDB and on partial reversal by efficacious therapy [41]. Therefore, atherosclerotic lesions and inflammatory processes, induced by intermittent hypoxia, contribute to long-term increased cardiovascular morbidity and mortality described in patients with SDB $[42,43]$.

In line with this hypothesis, the present authors found in healthy elderly subjects, free of major cardiovascular risk, an increased level of CRP associated with ODI without any effect on markers of chronic hypoxaemia, mean $\mathrm{Sp}_{\mathrm{p}} \mathrm{O}_{2}$ and time spent at $<90 \% \mathrm{Sp}_{\mathrm{p}} \mathrm{O}_{2}$, as well as apnoea frequency and sleep

TABLE 4 Logistic model coefficients for log C-reactive protein (CRP) by apnoea/hypopnoea index (AHI) severity

\begin{tabular}{|c|c|c|c|c|c|c|}
\hline & $A H I h^{-1}$ & Coefficient & SE & Chi-squared & p-value & OR (95\% Cl) \\
\hline Unadjusted model & $15-30$ & -0.045 & 0.086 & 0.25 & 0.605 & $0.96(0.81-1.13)$ \\
\hline \multirow[t]{2}{*}{ Adjusted model ${ }^{\#}$} & $15-30$ & -0.140 & 0.092 & 2.35 & 0.129 & $0.87(0.72-1.04)$ \\
\hline & $>30$ & 0.043 & 0.115 & 0.141 & 0.708 & $1.04(0.83-1.31)$ \\
\hline
\end{tabular}

OR: odds ratio; $\mathrm{Cl}$ : confidence interval. ${ }^{\#}$ : for sex, body mass index, hypertension, type 2 diabetes and current smoking status 


\begin{tabular}{|c|c|c|c|}
\hline \multirow[t]{2}{*}{ TABLE 5} & \multicolumn{3}{|c|}{$\begin{array}{l}\text { Logistic likelihood ratio tests table for oxygen } \\
\text { desaturation index }>10 \text { events } \cdot h^{-1}\end{array}$} \\
\hline & & Chi-squared & $\mathrm{p}$-value \\
\hline \multicolumn{2}{|l|}{ Sex male } & 31.22 & $<0.0001$ \\
\hline \multicolumn{2}{|l|}{ BMI $^{\#}$} & 24.28 & $<0.0001$ \\
\hline \multicolumn{2}{|c|}{ Type 2 diabetes } & 9.93 & 0.0016 \\
\hline \multicolumn{2}{|c|}{ Log CRP $\mathrm{mg} \cdot \mathrm{L}^{-1}$} & 7.45 & 0.0064 \\
\hline \multicolumn{2}{|c|}{ Hypertension } & 4.80 & 0.028 \\
\hline \multicolumn{2}{|c|}{ Current/past smoker } & 1.06 & 0.305 \\
\hline
\end{tabular}

fragmentation. This association persisted after adjustment for hypertension, obesity and diabetes, stressing the link between the hypoxia-re-oxygenation factor and increased circulation levels of atherogenic inflammatory mediators. One interesting finding was that the strongest independent factor associated with CRP levels was the ODI, even if the degree of overnight hypoxaemic load was mild. Although speculative, these results may be explained by two factors. First, the recurrence of hypoxaemia in itself, independent of the severity of hypoxaemia $[35,36,40]$ and, secondly, the age-related vascular changes inducing a greater reaction to the ischaemiare-oxygenation process in the elderly even when the hypoxaemic level is moderate.

The key role of mild-to-moderate intermittent hypoxaemia on CRP levels and the lack of AHI and sleep fragmentation effect in the current elderly subjects may explain some of the reported age-related differences on cardiovascular risk. The mortality risk in SDB is greater in patients with an AHI $>20$ events $\cdot h^{-1}[44,45]$, an effect, however, significant only for middle-aged patients. Moreover, the morbidity for hypertension, heart failure and stroke $[44,45]$ is related to the AHI in 50 -yr-old patients, an association, however, not significant or acting in the reverse direction when older patients are considered [46, 47]. Therefore, the present authors can conclude that in the elderly, atherosclerotic and inflammatory processes are dependent on intermittent hypoxaemic load, a more potent stimulus for sympathetic activation and hypertension than the AHI and sleep fragmentation. The age-related remodelling of the vascular system may affect this association and mild-to-moderate hypoxaemia is sufficient, in itself, to activate inflammatory processes.

Even though the strength of the current study lies in the analysis of a large number of elderly subjects free from stroke and heart failure, some limitations should be considered. First, that an unknown sub-clinical cardiovascular disease cannot be ruled out in the present study subjects. However, the importance of such findings in the association between CRP levels and ODI was limited by the exclusion of subjects with prevalent medical conditions and by adjustment for covariates such as diabetes, hypercholesterolaemia and BMI. Secondly, despite a wide spectrum of SDB being present in the current population, mild cases were prevalent, the absence of severe cases may reduce the relationship between CRP and AHI. However, this finding is common in clinical and epidemiological studies; severe cases are more common in young patients [48]. Thirdly, the examined elderly subjects were noninstitutionalised and therefore they might constitute a survivor group more resistant to vascular risk and stress. This latter possibility could be suggested by the different clinical aspects of SDB in the elderly, in which neither sleepiness nor common predisposing factors appear strongly related to apnoea density [49]. Finally, in the present population, the nocturnal sleep study was performed by polygraphy, which could give both an overestimation of the incidence of positive SDB cases and a crude estimate of the real sleep fragmentation. Since autonomic arousals are actually considered as sensitivity markers of sleep fragmentation [32] the lack of association between CRP levels, the AHI and AAI exclude a primary key role of apnoea density and sleep fragmentation on the activation of inflammatory processes in SDB.

In conclusion, the current study shows that intermittent nocturnal hypoxaemia is associated with elevated C-reactive protein levels in healthy elderly subjects with sleep apnoea. After adjustment for confounding factors, oxyhaemoglobin desaturations, i.e. recurrent hypoxaemia/reoxygenation events, are the only significant factors associated with inflammatory processes in sleep-disordered breathing, apnoea/hypopnoea density and sleep fragmentation showed no such association. The eventual cardiovascular consequences of such observations need to be explored by prospective studies examining the longterm outcomes of such patients and the usefulness of nocturnal ventilatory support.

\section{REFERENCES}

1 Shahar E, Whitney CW, Redline S, et al. Sleep-disordered breathing and cardiovascular disease: cross-sectional results of the Sleep Heart Health Study. Am J Respir Crit Care Med 2001; 163: 19-25.

2 Newman AB, Nieto FJ, Guidry U, et al. Relation of sleepdisordered breathing to cardiovascular disease risk factors: the Sleep Heart Health Study. Am J Epidemiol 2001; 154: 50-59.

3 Young T, Palta M, Dempsey J, Skatrud J, Weber S, Badr S. The occurrence of sleep disordered breathing in middleage adults. N Engl J Med 1993; 328: 1230-1235.

4 Nieto FJ, Young TB, Lind BK, et al. Association of sleepdisordered breathing, sleep apnea, and hypertension in a large community-based study. Sleep Heart Health Study. JAMA 2000; 283: 1829-1836.

5 Sin DD, Fitzgerald F, Parker JD, Newton G, Floras JS, Bradley TD. Risk factors for central and obstructive sleep apnea in 450 men and women with congestive heart failure. Am J Respir Crit Care Med 1999; 160: 1101-1106.

6 Baguet JP, Hammer L, Levy P, et al. The severity of oxygen desaturation is predictive of carotid wall thickening and plaque occurrence. Chest 2005; 128: 3407-3412.

7 Phillips BG, Somers VK. Neural and humeral mechanisms mediating cardiovascular responses to obstructive sleep apnea. Resp Physiol 2000; 119: 181-187.

8 Pober JS, Gimbrone MA, Lapiette LA et al, Overlapping patterns of activation of human endothelial cells by 
interleukin-1, tumor necrosis factor and immune interferon. J Immunol 1986; 137: 1893-1896.

9 Lavie L, Kraiczi H, Hefetz A, et al. Plasma vascular endothelial growth factor in sleep apnea syndrome: effects of nasal continuous positive air pressure treatment. Am J Respir Crit Care Med 2002; 165: 1624-1628.

10 Vgontzas AN, Bixler EO, Chrousos GP. Sleep apnea is a manifestation of the metabolic syndrome. Sleep Med Reviews 2005; 9: 211-224.

11 Ross R. The pathogenesis of atherosclerosis: a prospective for the 1990s. Nature 1993; 362: 801-809.

12 Pasceri V, Willerson JT, Yeh ET. Direct proinflammatory effect of C-reactive protein on human endothelial cells. Circulation 2000; 102: 2165-2168.

13 Ridker PM, Hennekens $\mathrm{CH}$, Buring JE et al, C-reactive protein and other markers of inflammation in the prediction of cardiovascular disease in women. $N$ Engl J Med 2000; 342: 836-843.

14 Punjabi NM, Beamer BA. C-reactive protein is associated with sleep disordered breathing independent of adiposity. Sleep 2007; 30: 29-34.

15 Yokoe T, Minoguchi K, Matsuo H, et al. Elevated levels of C-reactive protein and interleukin-6 in patients with obstructive sleep apnea syndrome are decreased by nasal continuous positive airway pressure. Circulation 2003; 107: 1129-1134.

16 Shamsuzzaman AS, Winnicki M, Lanfranchi $\mathrm{P}$, et al. Elevated C-reactive protein in patients with sleep apnea. Circulation 2002; 105: 2462-2464.

17 Teramoto S, Yamamoto H, Yamaguchi Y, Namba R, Ouchi Y. Obstructive sleep apnea causes systemic inflammation and metabolic syndrome. Chest 2005; 127: 1074-1075.

18 Teramoto S, Yamamoto H, Ouchi Y. Increased C-reactive protein and increased plasma interleukin-6 may sinergically affect the progression of coronary atherosclerosis in obstructive sleep apnea syndrome. Circulation 2003; 107: e40.

19 Yao M, Tachibana N, Okura M, et al. The relationship between sleep-disordered breathing and high-sensitivity C-reactive protein in Japanese men. Sleep 2006; 29: 661-665.

20 Larkin EK, Rosen CL, Kirchner HL, et al. Variation of Creactive protein levels in adolescents: association with sleep-disordered breathing and sleep duration. Circulation 2005; 111: 1978-1982.

21 Tauman R, Ivanenko A, O'Brien LM, Gozal D. Plasma Creactive protein levels among children with sleep-disordered breathing. Pediatrics 2004; 113: 564-569.

22 Guilleminault C, Kirisoglu C, Ohayon MM. C-reactive protein and sleep-disordered breathing. Sleep 2004; 27: 1507-1511.

23 Kaditis AG, Alexopoulos EI, Kalampouka E, et al. Morning levels of C-reactive protein in children with obstructive sleep-disordered breathing. Am J Respir Crit Care Med 2005; 171: 282-286.

24 Danesh J, Whincup P, Walker M, et al. Low grade inflammation and coronary heart disease: prospective study and updated meta-analysis. BMJ 2000; 321: 199-204.

25 Ancoli-Israel S, Kripke DF, Klauber MR, et al. Sleepdisordered breathing in community-dwelling elderly. Sleep 1991; 14: 486-495.

26 Mant A, Saunders NA, Eyland EA, Pond CD, Sawyer B, Saltman DC. Sleep habits and sleep related respiratory disturbance in an older population. In: Horne J, ed. Sleep '88. Stuttgart, Gustav Fischer Verlag, 1989; pp. 260-261.

27 Stradling JR, Pepperell JCT, Davies RJO. Sleep apnoea and hypertension: proof at least? Thorax 2001; 56: Suppl. II, 45-49.

28 Lavie P, Herer P, Peled R, et al. Mortality in sleep apnea patients: a multivariate analysis of risk factors. Sleep 1995; 18: 149-157.

29 Marin MJ, Carrizo SJ, Vicente E, Agusti AG. Long term cardiovascular outcomes in men with obstructive sleep apnoea-hypopnoea with or without treatment with continuous positive airway pressure: an observational study. Lancet 2005; 365: 1046-1053.

30 Barthélémy JC, Pichot V, Dauphinot V, et al. Autonomic nervous system activity and decline as prognostic indicators of cardiovascular and cerebrovascular events. The PROOF Study. Study design and population sample. Associations with sleep-related breathing disorders: the 'SYNAPSE' Study. Neuroepidemiology 2007; 29: 18-28.

31 Sleep-related breathing disorders in adults: recommendations for syndrome definition and measurement techniques in clinical research. The report of an American Academy of Sleep Medicine Task Force. Sleep 1999; 22: 667-689.

32 Pitson DJ, Stradling JR. Autonomic markers of arousal during sleep in patients undergoing investigation for obstructive sleep apnoea: their relationship to EEG arousals, respiratory events and subjctive sleepiness. J Sleep Res 1998; 7: 53-59.

33 Herer B, Roche N, Carton M, Roig C, Poujol V, Huchon G. Value of clinical, functional, and oximetric data for prediction of obstructive sleep apnea in obese patients. Chest 1999; 116: 1537-1544.

34 Verma S, Miller AW, Busija DW. Endothelium antagonism and insulin's vascular effects. Hypertension 2002; 40: e12-e13.

35 Fletcher EC. Effect of episodic hypoxia on sympathetic activity and blood pressure. Respir Physiol 2000; 119: 189-197.

36 Prabhakar NR. Sleep apnea. An oxidative stress? Am J Respir Crit Care Med 2002; 165: 859-860.

37 Prabhakar NR. Oxygen sensing during intermittent hypoxia: cellular and molecular mechanisms. J Appl Physiol 2001; 90: 1986-1994.

38 Ryan S, Taylor CT, McNicholas WT. Selective activation of inflammatory pathways by intermittent hypoxia in obstructive sleep apnea syndrome. Circulation 2005; 112: 2660-2667.

39 Dyugovskaya L, Lavie P, Lavie L. Increased adhesion molecules expression and production of reactive oxygen species in leukocytes of sleep apnea patients. Am J Respir Crit Care Med 2002; 165: 934-939.

40 Savransky V, Nanayakkara A, Jianguo L, et al. Chronic intermittent hypoxia induces atherosclerosis. Am J Respir Crit Care Med 2007; 175: 1290-1297.

41 Drager LF, Bortolotto LA, Figueireido AC, Krieger EM, Lorenzi GE. Effects of continuous positive airway pressure on early signs of atherosclerosis in obstructive sleep apnea. Am J Respir Crit Care Med 2007; 176: 706-712.

42 Young T, Finn L, Peppard PE, et al. Sleep disordered breathing and mortality: eighteen-year follow-up of the Wisconsin sleep cohort. Sleep 2008; 31: 1071-1078.

43 Marshall NS, Wong KKH, Liu PY, Cullen SR, Knuiman MW, Grunstein RR. Sleep apnea as an independent risk factor for 
all-cause mortality: the Busselton health study. Sleep 2008; 31: 1079-1085.

44 He J, Kryger MH, Zorick FJ, et al. Mortality and apnea index in obstructive sleep apnea. Experience in 385 male patients. Chest 1988; 94: 9-14.

45 Lavie P, Herer P, Peled R, et al. Mortality in sleep apnea patients: a multivariate analysis of risk factors. Sleep 1995; 18: 149-157.

46 Munoz R, Duran-Cantolla J, Martinez-Vila E, et al. Severe sleep apnea and risk of ischemic stroke in the elderly. Stroke 2006; 37: 2317-2321.
47 Bixler EO, Vgontzas AN, Lin HM, Tyson K, Kales A. Association of hypertension and sleep-disordered breathing. Arch Intern Med 2000; 160: 2289-2295.

48 Bixler EO, Vgontzas AN, Ten Have T, et al. Effects of age on sleep apnea in men: I. Prevalence and severity. Am J Respir Crit Care Med 1998; 157: 144-148.

49 Bixler EO, Vgontzas AN, Lin HM, Calhoun SL, VelaBueno A, Kales A. Excessive daytime sleepiness in a general population sample: the role of sleep apnea, age, obesity, diabetes and depression. J Clin Endocrinol Metab 2005; 90: 4510-4516. 